\title{
PRIORIZAÇÃO DE LOCAIS DE COLETA PARA ISOLAMENTO DE BACILLUS ANTHRACIS NA ANTÁRTICA POR PROCESSO DE ANÁLISE HIERÁRQUICA
}

\author{
Luiz Octávio Gavião \\ Escola Superior de Guerra (ESG) \\ Fortaleza de São João - Av. João Luiz Alves, s/nº - Urca - Rio de Janeiro-RJ - CEP: 22291-090 \\ E-mail: luiz.gaviao67@gmail.com \\ Adriana Marcos Vivoni \\ Fundação Oswaldo Cruz \\ Avenida Brasil 4365 - Pavilhão Rocha Lima sala 312 - Manguinhos - RJ - CEP 21040360 \\ E-mail: avivoni@ioc.fiocruz.br
}

\begin{abstract}
RESUMO
O Programa Antártico Brasileiro se desenvolve com o apoio da Marinha, através dos seus navios e da Estação Antártica Comandante Ferraz (EACF). Entretanto, as condições climáticas, meteorológicas e hidrográficas do continente Antártico são rigorosas e instáveis. Isto dificulta, e por vezes impede, o cumprimento do apoio logístico às pesquisas, exigindo flexibilidade e constante adaptação na programação do apoio às equipes de pesquisadores. Nesse contexto, a priorização dos locais de coleta de amostras e das demais pesquisas científicas é essencial para minimizar o impacto das dificuldades de apoio. Esse problema de pesquisa foi aplicado ao projeto da Fundação Oswaldo Cruz, denominado FIOANTAR, a partir de uma amostra de dez locais de coleta pré-selecionados para a pesquisa de Bacillus Anthracis. Foi aplicado um modelo de apoio à decisão, com base no Processo de Análise Hierárquica (AHP). O AHP foi modelado por análise de custo-benefício, a partir da avaliação dos benefícios pelos próprios pesquisadores e da avaliação dos custos e riscos do apoio pelos especialistas da MB. Os resultados foram satisfatórios, indicando uma prioridade para eventual necessidade de escolha de locais de coleta.
\end{abstract}

Palavra-chave: Antártica; FIOANTAR; Bacillus Anthracis; AHP

\begin{abstract}
The Brazilian Antarctic Program is being developed with the support of the Brazilian Navy through its ships and the Comandante Ferraz Antarctic Station (EACF). However, the climatic, meteorological and hydrographic conditions of the Antarctic continent are severe and unstable. This makes it difficult, and sometimes prevents, the fulfillment of logistical support for research, requiring flexibility and constant adaptation in the programming of support to research teams. In this context, prioritization of sample collection sites and other scientific research is essential to minimize the logistical problems. This research was applied to the Oswaldo Cruz Foundation project, called FIOANTAR, from a sample of ten preselected collection sites for Bacillus Anthracis research. A decision support model was applied based on the Analytical Hierarchical Process (AHP). The AHP was modeled by costbenefit analysis, based on the researchers' benefit assessment and the cost-risk assessment of experts' support. The results were satisfactory, indicating a priority to choose collection sites.
\end{abstract}

Keywords: Brazilian ports; DEA; investment.

\section{Como Citar:}

GAVIÃO, Luiz Octávio; VIVONI, Adriana Marcos. Priorização de locais de coleta para isolamento de Bacillus anthracis na Antártica por Processo de Análise Hierárquica. In: SIMPÓSIO DE PESQUISA OPERACIONAL E LOGÍSTICA DA MARINHA, 19., 2019, Rio de Janeiro, RJ. Anais [...]. Rio de Janeiro: Centro de Análises de Sistemas Navais, 2019 


\section{INTRODUÇÃO}

O Programa Antártico Brasileiro se desenvolve com o apoio da Marinha do Brasil, através dos seus navios de apoio e da Estação Antártica Comandante Ferraz (EACF). A EACF está localizada na península Keller, ilha do Rei George, a $130 \mathrm{~km}$ da Península Antártica, na baía do Almirantado, Antártica. Desde 1984, diversas pesquisas têm sido realizadas em solo antártico, contribuindo para o desenvolvimento científico mundial. Em 2012, um incêndio nos geradores de energia destruiu a EACF, que deverá ser reinaugurada em 2020. As novas instalações terão a capacidade de acomodar até 64 pessoas e 17 laboratórios, além de alojamentos e espaços de convivência e de lazer [1].

A EACF presta diversos apoios diretos e indiretos às pesquisas. $\mathrm{O}$ grupo-base de militares apoia o abastecimento de materiais necessários às atividades científicas e logísticas, o transporte de pesquisadores, mantém a infraestrutura necessária às atividades operacionais, logísticas e administrativas e realiza a manutenção e reparo das unidades navais e aeronavais que participam das Operações Antárticas.

Entretanto, as condições climáticas, meteorológicas e hidrográficas do continente Antártico são rigorosas e instáveis. As temperaturas médias em sua região central variam entre $-30^{\circ} \mathrm{C}$ e $-65^{\circ} \mathrm{C}$, sendo a menor temperatura mundial, de $-89^{\circ} \mathrm{C}$, registrada na base russa de Vostok. O continente apresenta ventos fortes constantemente, com velocidades superiores a $70 \mathrm{~km} / \mathrm{h}$ nas costas e rajadas de $140 \mathrm{~km} / \mathrm{h}$. Em outras bases de pesquisa locais, já houve o registro de ventos superiores a $300 \mathrm{~km} / \mathrm{h}$ [2].

Esses aspectos de instabilidade ambiental dificultam, e por vezes impedem, o cumprimento do apoio logístico às pesquisas brasileiras, exigindo flexibilidade e constante adaptação na programação do apoio às equipes de pesquisadores. Uma rápida mudança climática pode prejudicar o lançamento ou recolhimento de equipes por embarcação ou por helicópteros, por exemplo. Nesse contexto, a priorização dos locais de coleta de amostras e demais pesquisas científicas é essencial para o cumprimento do programa de apoio logístico aos pesquisadores e para minimizar o impacto das dificuldades logísticas causadas pela instabilidade ambiental nos resultados dos estudos. Esse é o problema de pesquisa explorado neste artigo.

A priorização de locais de coleta de amostras é tipicamente um problema de apoio à decisão. Diversas metodologias podem ser empregadas neste tipo de problema. A escolha pelo Processo de Análise Hierárquica (AHP), desenvolvido por [3], traz algumas vantagens relevantes, no que se refere à simplicidade de cálculo, à facilidade de entendimento por parte dos tomadores de decisão e à natureza dos dados do problema.

O AHP foi modelado para uma análise de custo-benefício, com base em duas estruturas hierárquicas. Metade do problema se concentrou nos benefícios à pesquisa científica, a partir da avaliação dos próprios pesquisadores. A outra metade do problema se referiu aos custos e riscos do apoio logístico aos locais de coleta, a partir da avaliação de especialistas da Secretaria da Comissão Interministerial de Recursos do Mar (SECIRM), responsáveis por essa tarefa nos navios e na EACF. O AHP permite esse tipo de análise de custo-benefício, priorizando os locais de coleta com a maior razão de benefícios em relação aos custos e riscos do apoio logístico, conforme proposto em [4].

Nesse sentido, o artigo foi dividido em cinco seções. Após a introdução, a Seção 2 traz as características e necessidades de apoio do Projeto FIOANTAR, desenvolvido pela Fundação Oswaldo Cruz (FIOCRUZ) junto ao Programa Antártico Brasileiro (PROANTAR). A Seção 3 apresenta o método AHP e seus procedimentos de cálculo. A Seção 4 realiza a aplicação do método ao problema, incluindo a análise dos resultados. Por 
fim, a Seção 5 conclui o trabalho.

\section{O PROJETO FIOANTAR}

Diversas pesquisas indicam que a Antártica constitui uma biosfera rica e variada, basicamente em termos de microrganismos, muitos dos quais com características especiais. Entretanto, as interligações e os impactos dos ecossistemas antárticos sobre a saúde dos animais, dos visitantes, ou sobre o próprio continente e a América do Sul foram pouco estudados. A biodiversidade antártica pode revelar novos ecossistemas e nova extensão taxonômica, capaz de ser aplicada no desenvolvimento de biotecnologias, de novas enzimas e de (bio)fármacos [5].

Uma série de atividades da comunidade global justifica a realização de pesquisas em solo antártico. Entre essas atividades destacam-se: o avanço da circulação oceânica de lixo; o crescente turismo nas calotas polares; os desprendimentos de icebergs; a exposição de camadas inferiores de gelo e de solo pelo aumento da temperatura global. Nesse contexto, especula-se qual o potencial impacto da dinâmica da circulação e dispersão de espécies de potencial patogênico para além do oceano antártico, tanto das espécies autóctones como daquelas importadas pelo homem para a saúde humana e animal [5].

O projeto FIOANTAR tem por finalidade identificar patógenos novos e conhecidos, nos ecossistemas locais ou em continentes próximos. Vírus, bactérias, fungos e helmintos podem ser encontrados na camada ativa do solo, no permafrost, em águas marinhas e lacustres que banham o continente antártico e parasitam espécies de animais que lá vivem ou circulam. As pesquisas também podem avaliar a diversidade genética, a virulência e as capacidades metabólica e genômica dos microrganismos e vírus isolados [5].

\subsection{COLETA DE AMOSTRAS BIOLÓGICAS E AMBIENTAIS PARA ISOLAMENTO DE BACILLUS ANTHRACIS E BACILLUS CEREUS}

Uma parcela específica do FIOANTAR se refere à pesquisa de bactérias do gênero Bacillus e correlatos, em especial às espécies patogênicas Bacillus anthracis e Bacillus cereus, em camada ativa de solo (i.e camada que sofre descongelamento durante o verão e, por consequência, ação de fatores ambientais), no permafrost antártico (i.e. solo permanentemente congelado), em fezes de animais e excretas de aves. Essas bactérias afetam humanos e animais. Por serem capazes de desenvolverem formas dormentes, metabolocamente inativas, denominadas esporos, apresentam grande resistência às condições ambientais extremas e podem persistir no ambiente por longos períodos. Em caso de isolamento de cepas, o estudo detalhado das mesmas trará informações únicas sobre a evolução, epidemiologia e ecologia desses patógenos [5].

O B. anthracis é causador do carbúnculo hemático, também chamado de Antraz, uma doença zoonótica, septicêmica, hemorrágica e letal que acomete principalmente ruminantes domésticos e selvagens e, de forma ocasional, humanos [6]-[9]. O Antraz também é comumente encontrado em episódios de guerra biológica [10]. O B. cereus é um reconhecido patógeno alimentar, capaz de produzir diversas toxinas, muitas delas implicadas na patogênese de intoxicação alimentar. Além desses quadros, o B. cereus é capaz de causar diversas infecções, sistêmicas e localizadas, em indivíduos imunocomprometidos e imunocompetentes [11]. O espectro de infecções não-gastrointestinais inclui bacteremia fulminante, infecções do sistema nervoso central (meningite e abscessos), endofitalmite, pneumonia e infecções semelhantes à gangrena gasosa.

A resistência dos esporos e a diversidade fisiológica das formas vegetativas fazem com que as espécies do Gênero Bacillus sejam consideradas ubíquas, podendo ser isoladas em ambientes como solo, água, em gêneros alimentícios e em espécimes clínicos. Os esporos 
de $B$. anthracis e $B$. cereus são resistentes à secagem, à radiação e a desinfetantes, e podem permanecer viáveis por anos no solo. [12] descrevem os diversos mecanismos que proporcionam a sobrevivência desses esporos em diversos ambientes extremos, inclusive extraterrestres, em condições extremas de temperatura, pressão e exposição a diversas formas de radiação.

Tanto o B. anthracis quanto o B. cereus já foram isolados de amostras de solos do permafrost siberiano. [13] descreveram o isolamento de uma cepa de $B$. cereus de uma amostra de solo do permafrost de cerca de três milhões de anos, coletada na Mammoth Mountain, na Sibéria. Essa cepa apresenta grande similaridade genética com cepas modernas de $B$. cereus, e seus esporos foram capazes de sobreviver às condições extremas de temperatura e privação de fontes energéticas. Regiões localizadas em elevadas latitudes na Sibéria, como a península de Yamal, vem sofrendo por séculos com recorrentes surtos de Antraz em animais e humanos. Sabe-se que, nessas regiões, surtos recentes estão ligados ao descongelamento do permafrost e à exposição de solos contaminados, antes inacessíveis [14].

O isolamento de membros do gênero Bacillus e de outros Firmicutes em solos antárticos já foi descrito por [15], indicando potencial presença de patógenos como B. cereus e $B$. anthracis. Há relatos na literatura sobre a presença de $B$. anthracis em fezes de aves, principalmente aquelas consideradas carniceiras [16]-[18]. A presença de aves migratórias na região que se alimentam fora do ambiente antártico, mas deixam seus excretas na região, traz um elemento interessante para a investigação da presença de $B$. anthracis e $B$. cereus no continente: a avaliação desses indivíduos como possíveis vetores de cepas exógenas.

\subsection{LOCAIS DE COLETA}

Com base em pesquisas anteriores, uma série de locais foram pré-selecionados para a coleta de amostras de solo, de permafrost, de fezes de animais e de excretas de aves. A seleção foi baseada na presença de fatores de interesse para o isolamento dos diversos patógenos a que o FIOANTAR se propõe a estudar, não exclusivamente $B$. anthracis e $B$. cereus. A Fig. 1 descreve os dez pontos na Ilha Rei George, onde está localizada a EACF e a Ilha Nelson. A numeração dos locais manteve a designação completa do projeto FIOANTAR, que inclui outros pontos não relacionados a essa pesquisa [5].
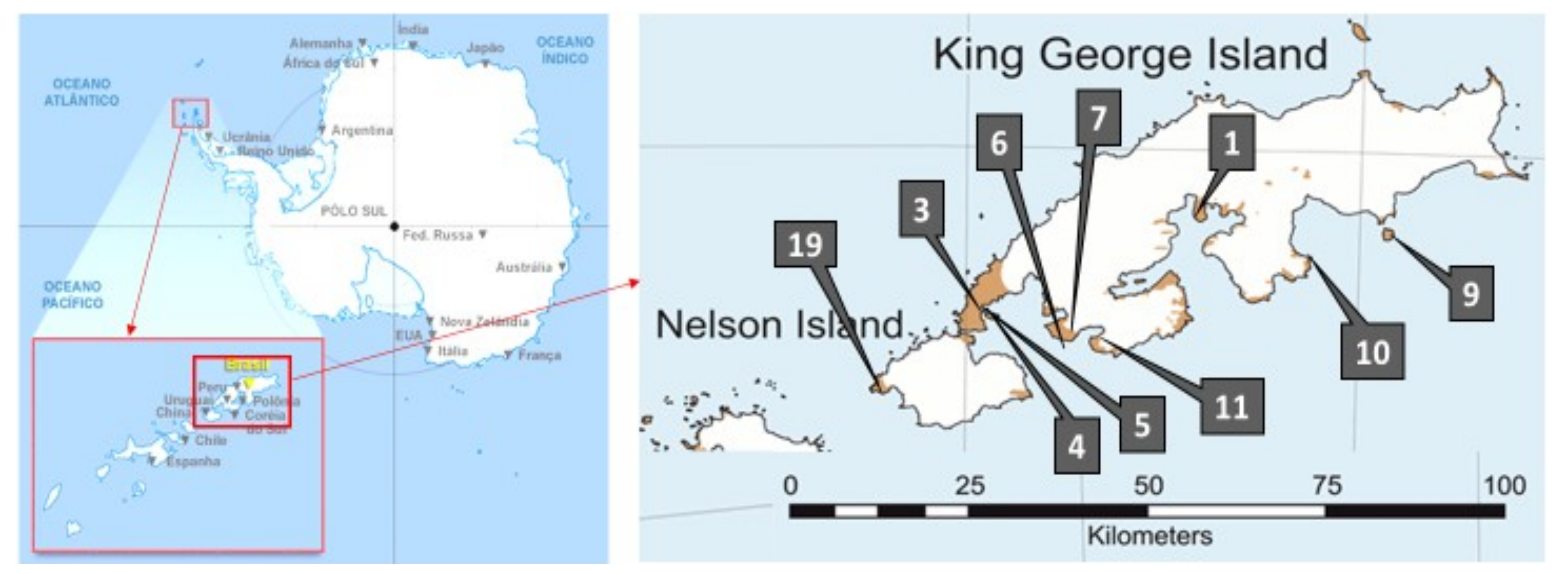

Fig 1- Locais de coleta nas Ilhas Rei George e Nelson

Os seguintes pontos estão indicados na Fig. 1: (1) Península Keller (EACF); (3) 
Península Fildes (Long Lake); (4) Península Fildes (Ardley Island - Lake, Luis Point); (5) Península Fildes (Ardley Island - Faro Point); (6) Lago da Península Barton (South Spit); (7) Glaciar da Península Barton; (9) Ilha Pinguim; (10) Lions Rump; (11) Península Potter e (19) Ilha Nelson - Harmony point.

\section{METODOLOGIA}

O AHP, proposto por [3], é uma abordagem muito popular para a tomada de decisão multicritério (MCDM). O AHP tem sido aplicado há quase quatro décadas em ampla gama de problemas que requerem o apoio à decisão nos mais diversos campos do conhecimento. $\mathrm{O}$ método utiliza uma matriz de decisão recíproca, obtida por comparações pareadas, a partir de dados qualitativos ou quantitativos. A comparação pareada foi introduzida por [19] e posteriormente desenvolvida por [20]. O AHP explora essa abordagem com uma hierarquia de subproblemas, de forma a simplificar o processo de avaliação. A estrutura hierárquica de um problema modelado pelo AHP pode ser descrita, genericamente, através da Fig. 2.

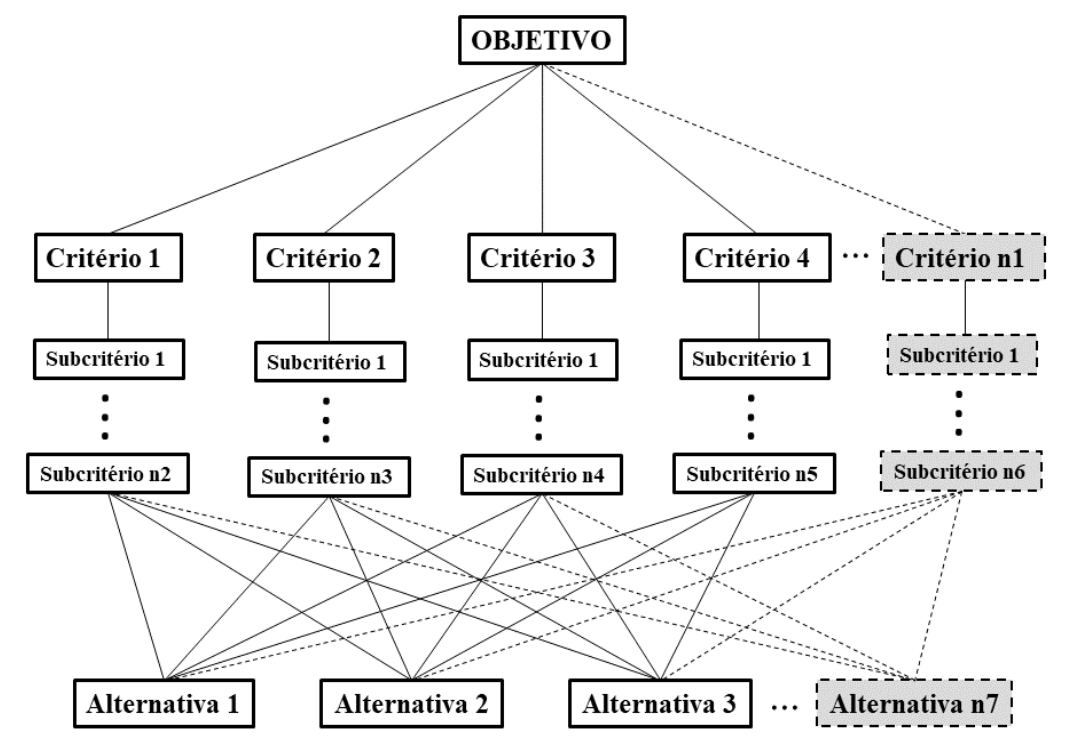

Fig. 2 - Estrutura hierárquica do AHP

Após construir o modelo hierárquico, deve-se realizar uma comparação pareada em cada nível da estrutura, com base na escala de Saaty, descrita na Fig. 3. Essa escala de nove pontos apresenta informações psicométricas para avaliar os pares de critérios, subcritérios e alternativas, sob a forma de expressões linguísticas. Assim, o avaliador pode considerar um critério "equivalente" a outro, um subcritério "mais importante" que outro, uma alternativa "menos importante" que outra. Cada comparação qualitativa do avaliador é traduzida em um número da escala, para compor uma matriz similar a da Equação (1).

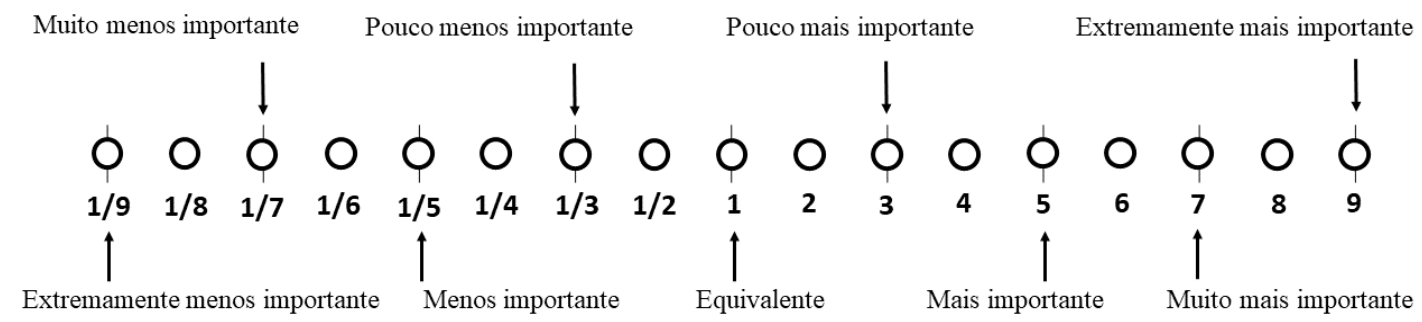


No método de comparação pareada, os critérios, eventuais subcritérios e alternativas são avaliados por especialistas ou tomadores de decisão. Considerando, por exemplo, o nível dos critérios da Fig.2, a comparação pareada dos "n” critérios produz uma matriz quadrada (n x n) de avaliação, conforme indicada na Equação (1).

$$
A=\left[\begin{array}{cccc}
1 & a_{12} & \ldots & a_{1 n} \\
1 / a_{12} & 1 & \ldots & a_{2 n} \\
\vdots & \vdots & \ddots & \vdots \\
1 / a_{1 n} & 1 / a_{2 n} & \ldots & 1
\end{array}\right]
$$

Na matriz A, $a_{i j}=1 / a_{j i}$ e quando $i=j, a_{i j}=1$, por se tratarem de elementos equivalentes. $\mathrm{Na}$ sequência de cálculos do AHP, deve-se normalizar a matriz de decisão, de forma que cada valor $a_{i j}$ seja dividido pela soma dos valores existentes em cada coluna. Em seguida, são calculadas as prioridades médias locais (PML), que correspondem às médias das linhas das matrizes normalizadas na etapa anterior. Finalmente, são obtidas as prioridades globais, a partir das médias das PML.

Para garantir a consistência dentro da matriz de comparação pareada, um índice de consistência (IC) foi definido de acordo com a Equação (2), em que $\lambda_{\max }$ se refere ao maior valor próprio da matriz de avaliações, e $n$ é o número de ordem da matriz recíproca. A taxa de consistência final (CR) é obtida pela Equação (3), com base no IC e nos índices de Inconsistência Aleatória (IR), descritos na Tabela 1, conforme a dimensão da matriz de avaliações. A consistência das avaliações é considerada satisfatória para RC inferior a 0,1 .

$$
I C=\frac{\lambda_{\max }-n}{n-1}
$$

Tabela 1 - Índices de Inconsistência Aleatória (IR)

\begin{tabular}{ccccccccccc}
\hline Dimensão da Matriz & 1 & 2 & 3 & 4 & 5 & 6 & 7 & 8 & 9 & 10 \\
\hline IR & 0 & 0 & 0,58 & 0,9 & 1,12 & 1,24 & 1,32 & 1,41 & 1,45 & 1,49 \\
\hline
\end{tabular}

$$
R C=\frac{I C}{I R}
$$

\section{APLICAÇÃO}

O problema de priorização dos locais de coleta de B. anthracis e B. cereus em solo antártico foi modelado por análise de custo-benefício. O modelo AHP pode ser utilizado com essa finalidade, a partir de duas estruturas hierárquicas diferentes: uma de critérios e subcritérios que caracterizam aspectos positivos do problema, definidos como benefícios e outra estrutura que caracteriza aspectos negativos, definidos como custos e riscos ao processo de coleta. A análise de custo-benefício também pode ser efetuada por Processo de 
Análise de Redes (ANP), que se caracteriza por uma generalização do AHP. Entretanto, o AHP é mais simples de modelar, por considerar independentes as interações entre critérios e subcritérios [21], [22].

Com certa frequência, as alternativas a partir das quais uma escolha deve ser feita envolvem custos e benefícios associados a elas. Neste caso, é útil construir hierarquias separadas de custos e benefícios, com as mesmas alternativas no nível inferior de cada estrutura. Assim, obtém-se um vetor de prioridade de benefícios e um vetor de prioridade de custos. A razão entre esses vetores de benefícios e de custos é calculado para cada alternativa, com a maior taxa indicando a alternativa de maior prioridade. No caso em que os recursos são alocados para vários projetos, tais indicadores de benefício-custo podem ser valiosos para uma tomada de decisão mais técnica, com menor incidência de subjetividade [4].

Os benefícios foram avaliados por pesquisadores participantes do projeto FIOANTAR, enquanto os custos foram avaliados por Oficiais de Marinha com experiência em operações de lançamento e recolhimento de pesquisadores a partir dos navios de apoio antártico e da SECIRM. Para a hierarquia de benefícios, foram selecionados três critérios de avaliação para os dez locais de coleta, com base no potencial de retorno científico em relação à presença de animais e o tipo de animais em questão (mamíferos, aves), presença e tipo de vegetação (líquens, briófitas, plantas superiores) e tipos de solo nos locais. Para a hierarquia de custos e riscos, a equipe da Marinha selecionou os critérios de custos do apoio logístico, os riscos à navegação e voo de aeronaves e riscos de alterações ambientais que envolvem a infiltração e resgate de equipes aos locais de coleta. As hierarquias de benefícios e custos estão descritas na Fig. 4.
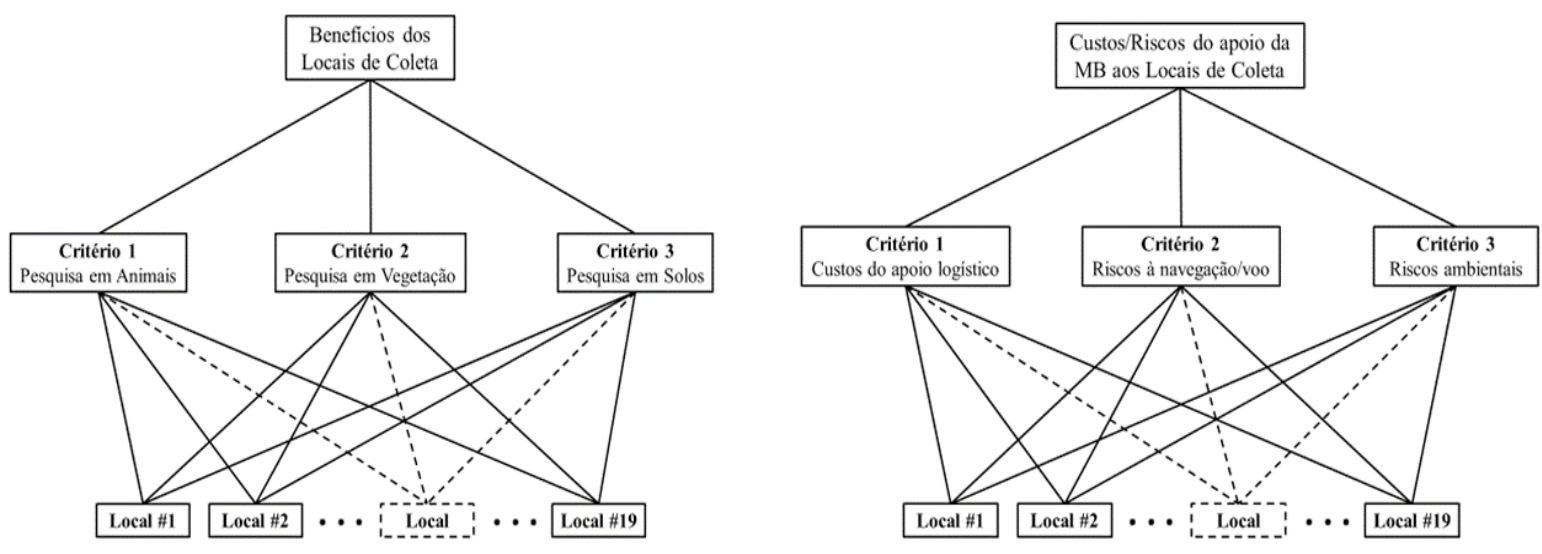

Fig. 4 - Estrutura hierárquica de benefícios e custos/riscos

\subsection{CÁLCULO DO AHP POR MÉDIAS GEOMÉTRICAS}

Inicialmente foram consolidadas as matrizes de pontos com base nas médias geométricas das avaliações pareadas dos especialistas. Por exemplo, se em uma determinada avaliação da relevância do Critério 1 sobre o Critério 2 o valor da escala de Saaty para cinco especialistas foi $(2,1,4,1 / 5,1 / 3)$, o vetor representativo dessa avaliação seria 0,8800894, que corresponde à média geométrica das cinco avaliações. Assim, novas matrizes de julgamentos foram produzidas, a partir dessas médias das avaliações dos especialistas.

Em seguida, foi aplicado o método AHP, descrito nas Equações (1) a (3), sobre as 
estruturas da Fig. 4. Os seguintes pesos foram obtidos para os critérios e locais de coleta, para as hierarquias de benefícios e custos/riscos, conforme as Tabelas 2 e 3, respectivamente. A Tabela 4 consolida os resultados iniciais. A linha de pesos dessas tabelas indica os resultados do AHP para os critérios. Os resultados dos locais de coleta indicam os pesos dessas alternativas para cada critério. Os valores 0,1 para o critério solo, na Tabela 2, decorrem do consenso dos especialistas em relação à equivalência dos locais de coleta para esse critério.

Tabela 2 - Benefícios dos Locais por médias geométricas

\begin{tabular}{cllc}
\hline & C1 - Animais & C2 - Vegetação & C3 - Solo \\
\hline Pesos & 0,1075546 & 0,6965531 & 0,1958924 \\
\hline Locais & & & \\
1 & 0,1902673 & 0,09265149 & 0,1 \\
3 & 0,05767953 & 0,04486448 & 0,1 \\
4 & 0,1452194 & 0,04092187 & 0,1 \\
5 & 0,07041114 & 0,04195943 & 0,1 \\
6 & 0,0475769 & 0,04549161 & 0,1 \\
7 & 0,03893839 & 0,01904815 & 0,1 \\
9 & 0,06396531 & 0,1967204 & 0,1 \\
10 & 0,1295765 & 0,1332724 & 0,1 \\
11 & 0,1427146 & 0,1925351 & 0,1 \\
19 & 0,1136509 & 0,1925351 & 0,1 \\
\hline
\end{tabular}

Tabela 3 - Custos/Riscos dos Locais por médias geométricas

\begin{tabular}{clll}
\hline & C1 - ApLog & C2 - Nav/Voo & C3 - Amb \\
\hline Pesos & 0,09728707 & 0,6758905 & 0,2268224 \\
\hline Locais & & & \\
1 & 0,02314976 & 0,03947121 & 0,04565965 \\
3 & 0,07558877 & 0,130155 & 0,1355416 \\
4 & 0,04803247 & 0,130155 & 0,06394875 \\
5 & 0,04803247 & 0,130155 & 0,06394875 \\
6 & 0,05996151 & 0,08968242 & 0,04575176 \\
7 & 0,1394237 & 0,08968242 & 0,1890256 \\
9 & 0,1525297 & 0,1089203 & 0,09218957 \\
10 & 0,1568237 & 0,1089203 & 0,135815 \\
11 & 0,06596085 & 0,07844359 & 0,09223591 \\
19 & 0,2304971 & 0,09441483 & 0,1358833 \\
\hline
\end{tabular}

Tabela 4 - Resultados por médias geométricas

\begin{tabular}{clllc}
\hline & Benefícios & Custos/Riscos & Resultados & Prioridade \\
\hline $\begin{array}{c}\text { Locais } \\
1\end{array}$ & 0,10459 & 0,03928702 & 2,6622034 & 1
\end{tabular}




\begin{tabular}{clllc}
\hline & Benefícios & Custos/Riscos & Resultados & Prioridade \\
\hline Locais & & & & \\
3 & 0,05704342 & 0,1260682 & 0,4524807 & 9 \\
4 & 0,0637125 & 0,1071485 & 0,5946189 & 7 \\
5 & 0,05638925 & 0,1071485 & 0,5262722 & 8 \\
6 & 0,05639367 & 0,0768265 & 0,7340393 & 6 \\
7 & 0,03704528 & 0,1170549 & 0,3164779 & 10 \\
9 & 0,1634952 & 0,109368 & 1,4949083 & 3 \\
10 & 0,1263571 & 0,119681 & 1,0557823 & 5 \\
11 & 0,1690497 & 0,08035759 & 2,1037184 & 2 \\
19 & 0,1659238 & 0,1170599 & 1,4174271 & 4 \\
\hline
\end{tabular}

As RC obtidas após o cálculo das médias geométricas das avaliações estão descritas na Tabela 5. É possível verificar que as matrizes dos critérios de benefícios (B) e das avaliações dos locais de coleta, em relação ao critério “Animais” (Crit 1) geraram RC superiores a 0,1. Isto indica que as médias geométricas das avaliações produziram matrizes com inconsistência lógica. Em decorrência disto, optou-se por aplicar uma nova rodada de avaliações, por intermédio de um procedimento de simulação para as avaliações com CR superiores a 0,1. O procedimento de simulação torna-se interessante quando não é possível realizar uma nova rodada de avaliações com os mesmos especialistas, além de evitar eventuais inconsistências lógicas nas rodadas subsequentes. Todas as avaliações iniciais em relação aos critérios de custos (C) foram consistentes.

Tabela 5 - RC das matrizes de avaliação

\begin{tabular}{l|cc|ccc|ccc}
\hline $\mathrm{RC}$ & $\begin{array}{c}\text { Crit } \\
(\mathrm{B})\end{array}$ & $\begin{array}{c}\text { Crit } \\
(\mathrm{C})\end{array}$ & $\begin{array}{c}\text { Crit 1 } \\
(\mathrm{B})\end{array}$ & $\begin{array}{c}\text { Crit 2 } \\
(\mathrm{B})\end{array}$ & $\begin{array}{c}\text { Crit 3 } \\
(\mathrm{B})\end{array}$ & $\begin{array}{c}\text { Crit 1 } \\
(\mathrm{C})\end{array}$ & $\begin{array}{c}\text { Crit 2 } \\
(\mathrm{C})\end{array}$ & $\begin{array}{c}\text { Crit 3 } \\
(\mathrm{C})\end{array}$ \\
\hline $\begin{array}{l}\text { Critérios } \\
\text { Locais }\end{array}$ & 0,228 & 0,059 & & & & & & \\
\hline
\end{tabular}

\subsection{CÁLCULO DO AHP POR SIMULAÇÃo}

O procedimento de simulação foi necessário para buscar novas matrizes de avaliação, mantendo uma correspondência com os julgamentos e RC inferiores a 0,1. O AHP por simulação permite ampliar a quantidade de dados, em função das avaliações iniciais dos especialistas. Foram simulados cem mil valores aleatórios, entre as avaliações dos especialistas, para a criação de novas matrizes dos critérios de benefícios e para os locais de coleta, segundo o critério “Animais”. As demais avaliações foram mantidas, em função de seus resultados consistentes.

As simulações foram efetuadas a partir de distribuições Beta PERT. As médias geométricas das avaliações das matrizes inconsistentes foram utilizados como parâmetros modais das distribuições Beta PERT. Os parâmetros mínimos e máximos dessa distribuição foram os respectivos mínimo $(0,11)$ e máximo (9) da escala de Saaty. As distribuições Beta PERT são assimétricas e amplamente empregadas para a modelagem de problemas de análise de riscos, cujos parâmetros conhecidos se restringem aos mínimos, modais e máximos de uma variável aleatória contínua. Essas distribuições se assemelham às triangulares, porém permitem 
melhor ajuste dos dados, a partir de um parâmetro adicional de curtose (shape). Dependendo da maior ou menor precisão das avaliações, é possível ajustar o shape da distribuição Beta PERT para apresentar menor ou maior variância dos dados em relação à moda [23].

Por exemplo, para um determinado par de critérios, foram coletadas as estimativas dos especialistas, de tal forma que os parâmetros na escala de Saaty foram: mínimo (1/9), moda (5) e máximo (6). O parâmetro "shape” dessa distribuição indica o grau de precisão da moda dos dados: para um grupo de especialistas com sólida experiência e opiniões com certo consenso pode ser adotado um parâmetro superior a "4", enquanto para contextos de maior incerteza e variância dos dados, sugerem-se parâmetros inferiores a "4”. Esses quatro parâmetros definem a distribuição Beta PERT da Fig. 5. No software R, as funções da distribuição Beta PERT estão disponíveis no aplicativo "mc2d" [24].

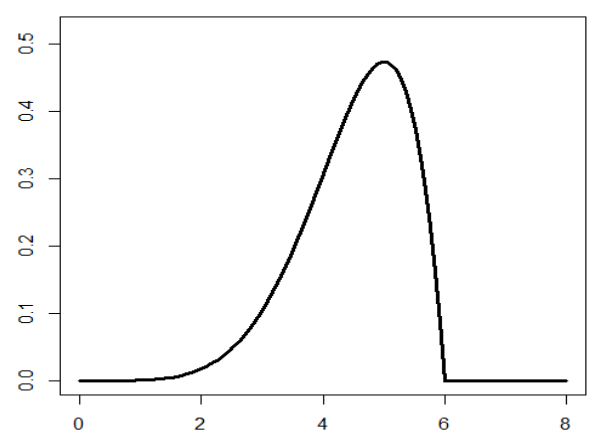

Fig. 5 Função densidade (PDF) da distribuição Beta PERT.

Definidas as distribuições de probabilidade de cada avaliação pareada dos critérios, é possível simular uma quantidade "n” de valores aleatórios. Esses valores compõem "n" matrizes de decisão para aplicação do AHP. Para cada matriz simulada, é calculada a CR das avaliações pareadas. No AHP com simulação é possível identificar a matriz que gera a mínima CR, que serve de referência ao cálculo dos pesos dos critérios [25]. Outro procedimento possível é computar as simulações que respeitam o valor limite de CR inferior a 0,1 e calcular as médias dos pesos das variáveis.

Das cem mil matrizes geradas por simulação, os cálculos do AHP revelaram que a média dos CR obtidos para os critérios foi de 0,036, indicando novos pesos aos critérios de benefícios: 0,2196239, 0,7129487 e 0,1834313, para os três critérios “Animais", "Vegetação" e "Solo", respectivamente, conforme a Tabela 6.

Para as avaliações dos locais de coleta, segundo o critério "Animais”, o novo CR médio foi de 0,092 , com os resultados também transcritos para a Tabela 6 . Os resultados dos locais de coleta para os critérios "Vegetação" e "Solo" foram mantidos da Tabela 2, pois apresentaram CR inferiores a 0,1.

Tabela 6 - Nova rodada para os Benefícios

\begin{tabular}{clll}
\hline & C1 - Animais & C2 - Vegetação & C3 - Solo \\
\hline Pesos & 0,2196239 & 0,5942206 & 0,1861555 \\
\hline Locais & & & \\
1 & 0,21129427 & Sem alteração & Sem alteração \\
3 & 0,08997215 & Sem alteração & Sem alteração \\
4 & 0,15286361 & Sem alteração & Sem alteração \\
5 & 0,08950513 & Sem alteração & Sem alteração
\end{tabular}




\begin{tabular}{clll}
\hline & C1 - Animais & C2 - Vegetação & C3 - Solo \\
\hline Pesos & 0,2196239 & 0,5942206 & 0,1861555 \\
\hline Locais & & & \\
6 & 0,06303547 & Sem alteração & Sem alteração \\
7 & 0,05609977 & Sem alteração & Sem alteração \\
9 & 0,06990086 & Sem alteração & Sem alteração \\
10 & 0,09461411 & Sem alteração & Sem alteração \\
11 & 0,09745803 & Sem alteração & Sem alteração \\
19 & 0,07525660 & Sem alteração & Sem alteração \\
\hline
\end{tabular}

Tabela 7 - Resultados por simulação

\begin{tabular}{clllc}
\hline & Benefícios & Custos/Riscos & Resultados & Prioridade \\
\hline Locais & & & & \\
1 & 0,12007625 & 0,03928702 & 3,0563847 & 1 \\
3 & 0,06503498 & 0,1260682 & 0,51587139 & 9 \\
4 & 0,07650467 & 0,1071485 & 0,71400615 & 7 \\
5 & 0,06320617 & 0,1071485 & 0,58989335 & 8 \\
6 & 0,0594917 & 0,0768265 & 0,77436429 & 6 \\
7 & 0,0422552 & 0,1170549 & 0,36098632 & 10 \\
9 & 0,15086276 & 0,109368 & 1,37940469 & 3 \\
10 & 0,11858828 & 0,119681 & 0,9908697 & 5 \\
11 & 0,15442799 & 0,08035759 & 1,9217599 & 2 \\
19 & 0,14955202 & 0,1170599 & 1,27756887 & 4 \\
\hline
\end{tabular}

A Tabela 7 traz os resultados obtidos com a nova rodada de simulações. O procedimento de simulação obteve êxito para reduzir os CR ao menor valor de inconsistência. Entretanto, verifica-se que as prioridades dos locais de coleta foram repetidas para o AHP por médias geométricas e por simulação. Assim, manteve-se a maior prioridade de benefícios, em relação aos custos e riscos, do Local 1, que coincide com as próprias instalações da EACF. Isto é coerente sob o ponto de vista prático, tendo em vista que a região, em geral, apresenta características similares ao potencial de pesquisa, enquanto a proximidade da Estação confere menores custos e riscos ao trabalho de apoio da Marinha aos pesquisadores.

Por outro lado, os locais de coleta 3, 5 e 7, que obtiveram as mais baixas prioridades, revelam alguma redundância com locais bem próximos. O local 4 pode apresentar características semelhantes aos locais 3 e 5, enquanto o local 6 é vizinho ao local 7. De maneira subliminar, o procedimento de avaliações pareadas permitiu revelar esses aspectos, contribuindo para a priorização de locais de coleta, em caso de necessidade de economia de meios ou mesmo por problemas de acessibilidade aos locais de pesquisa.

\section{CONCLUSÃO}

O projeto FIOANTAR tem caráter multidisciplinar, envolvendo equipes de diversos laboratórios, com diferentes especialidades, na formação do grupo de pesquisa. Em virtude disso, a seleção inicial de locais de coleta das amostras biológicas e ambientais foi realizada de forma a atender ao interesse de isolamento de microrganismos variados e de outros 
organismos, na tentativa de se obter os melhores resultados tanto para as equipes quanto para o grupo de pesquisa como um todo. Sendo assim, é provável que certos locais de coleta selecionados irão favorecer o isolamento de determinados patógenos em detrimento de outros.

Diante de um cenário climático desfavorável e da impossibilidade de se cobrir todos os pontos de coleta planejados, é de suma importância, principalmente no caso de patógenos com menor probabilidade de isolamento (como B. anthracis), priorizar os locais com maiores chances de ocorrência dos microrganismos em questão. Com relação ao isolamento de B. cereus e B. anthracis em território antártico, a ausência de dados publicados contribui para a dificuldade da seleção de locais adequados para coleta de amostras.

Nesse contexto, o presente trabalho demonstrou a utilização do modelo AHP no auxílio à decisão na escolha de pontos de coleta com base em dois focos distintos: a opinião de pesquisadores especialistas sobre quais seriam os pontos mais propensos a abrigarem $B$. cereus e B. anthracis; e a opinião dos especialistas do PROANTAR com relação aos custos e dificuldades logísticas envolvidos no acesso a cada local. Os resultados das análises forneceram uma lista de prioridade de locais de coleta que poderá servir como instrumento de apoio à decisão na escolha de pontos de coleta, em virtude de ocorrências indesejáveis que impossibilitem o acesso a todos os locais programados.

O modelo de apoio à decisão do AHP é simples, intuitivo, de fácil entendimento por parte dos tomadores de decisão e adequado à natureza dos dados do problema. O AHP foi modelado por análise de custo-benefício, a partir da avaliação dos benefícios pelos próprios pesquisadores e da avaliação dos custos e riscos do apoio pelos especialistas da MB. A análise de custo-benefício com o AHP proporcionou uma solução de compromisso entre a atividade-fim da pesquisa científica e a atividade-meio do apoio logístico da MB. Isto pode ser relevante no momento em que as partes negociam eventuais alterações do programa de apoio, tendo em vista a contribuição de ambas, de forma direta e igualmente ponderada, para os índices de custo-benefício.

Em relação às pesquisas futuras, algumas possibilidades são visualizadas. Inicialmente é possível ampliar a quantidade de especialistas, de forma a melhorar o ajuste dos dados às distribuições Beta PERT ou mesmo simular valores aleatórios com outros tipos de distribuição. A modelagem proposta com o AHP também pode ser aplicada aos demais grupos de pesquisa do FIOANTAR, tendo em vista a existência de outras listas de locais de coleta, ainda não submetidas a processo de priorização.

\section{REFERÊNCIAS BIBLIOGRÁFICAS}

[1] G. Mazui, "Marinha prevê inaugurar estação na Antártica em 2020, oito anos após incêndio," Portal G1, Brasília-DF, 16-Feb-2019.

[2] I. Izaguirre and G. Mataloni, Antártida, descubriendo el continente blanco. Editorial Del Nuevo Extremo, 2000.

[3] T. L. Saaty, The Analytic Hierarchy Process. New York: McGraw-Hill, 1980.

[4] T. L. Saaty and L. G. Vargas, Models, methods, concepts \& applications of the analytic hierarchy process, vol. 175. Springer Science \& Business Media, 2012.

[5] W. M. S. Degrave, "Projeto FIOANTAR,” Rio de Janeiro, 2019.

[6] M. Mock and A. Fouet, “Anthrax,” Annu. Rev. Microbiol., vol. 55, no. 1, pp. 647-671, 2001. 
[7] S. Davison, E. Couture-Tosi, T. Candela, M. Mock, and A. Fouet, "Identification of the Bacillus anthracis $\gamma$ phage receptor,” J. Bacteriol., vol. 187, no. 19, pp. 6742-6749, 2005.

[8] P. Vos et al., Bergey's manual of systematic bacteriology: Volume 3: The Firmicutes, vol. 3. Springer Science \& Business Media, 2011.

[9] M. Moayeri, S. H. Leppla, C. Vrentas, A. P. Pomerantsev, and S. Liu, "Anthrax pathogenesis,” Annu. Rev. Microbiol., vol. 69, pp. 185-208, 2015.

[10] A. M. Vivoni and L. O. Gavião, "O Bacillus anthracis (antraz) na guerra biológica: um análise sob o ponto de vista da mcirobiologia," Rev. Marítima Bras., vol. 138, no. 4/6, pp. 69-81, 2018.

[11] E. J. Bottone, "Bacillus cereus, a volatile human pathogen," Clin. Microbiol. Rev., vol. 23, no. 2, pp. 382-398, 2010.

[12] W. L. Nicholson, N. Munakata, G. Horneck, H. J. Melosh, and P. Setlow, "Resistance of Bacillus endospores to extreme terrestrial and extraterrestrial environments," Microbiol. Mol. Biol. Rev., vol. 64, no. 3 , pp. 548-572, 2000.

[13] E. V Brenner et al., "Draft genome sequence of Bacillus cereus strain F, isolated from ancient permafrost," Genome Announc., vol. 1, no. 4, pp. e00561-13, 2013.

[14] B. A. Revich and M. A. Podolnaya, "Thawing of permafrost may disturb historic cattle burial grounds in East Siberia," Glob. Health Action, vol. 4, no. 1, p. 8482, Dec. 2011.

[15] C. Bakermans, M. L. Skidmore, S. Douglas, and C. P. McKay, "Molecular characterization of bacteria from permafrost of the Taylor Valley, Antarctica," FEMS Microbiol. Ecol., vol. 89, no. 2, pp. 331-346, 2014.

[16] W. Beyer and P. Turnbull, “Anthrax in animals,” Mol. Aspects Med., vol. 30, no. 6, pp. 481-489, 2009.

[17] M. D. Saggese et al., "First Detection of Bacillus anthracis in Feces of Free-ranging Raptors from Central Argentina,” J. Wildl. Dis., vol. 43, no. 1, pp. 136-141, Jan. 2007.

[18] P. M. Lindeque and P. C. B. Turnbull, "Ecology and epidemiology of anthrax in the Etosha National Park, Namibia," Onderstepoort J. Vet. Res., vol. 61, no. 1, pp. 71-83, 1994.

[19] G. T. Fechner, “Elemente der Psychophysik (Breitkopf und Härtel, Leipzig).” Germany, 1860.

[20] L. L. Thurstone, “A law of comparative judgment.,” Psychol. Rev., vol. 101, no. 2, p. 266, 1994.

[21] T. L. Saaty, "Decision making - the analytic hierarchy and network processes (AHP/ANP)," J. Syst. Sci. Syst. Eng., vol. 13, no. 1, pp. 1-35, 2004.

[22] T. L. Saaty, "Making and validating complex decisions with the AHP/ANP," J. Syst. Sci. Syst. Eng., vol. 14, no. 1, pp. 1-36, 2005.

[23] D. Vose, Risk analysis: a quantitative guide. New York: John Wiley \& Sons, 2008.

[24] R. Pouillot and M. L. Delignette-Muller, "Evaluating variability and uncertainty separately in microbial quantitative risk assessment using two R packages," Int. J. Food Microbiol., vol. 142, no. 3, pp. 330$340,2010$.

[25] L. O. Gavião, A. P. Sant'Anna, G. B. A. Lima, and P. A. de A. Garcia, “CPP: Composition of Probabilistic Preferences. R package version 0.1.0.” R Core Team, Vienna, p. 24, 2018. 